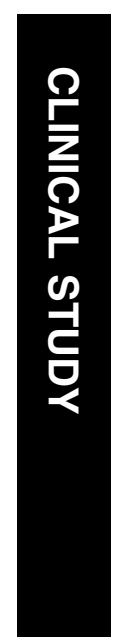

\title{
The influence of soft contact lenses on the intraocular pressure measurement
}

${ }^{1}$ Department of

Ophthalmology, Turgut Ozal Medical Center, Inonu

University, Malatya, Turkey

${ }^{2}$ Department of Ophthalmology, State Hospital, Malatya, Turkey

${ }^{3}$ Department of Ophthalmology, State Hospital, Sırt, Turkey

${ }^{4}$ Department of Ophthalmology, State Hospital, Kahramanmaras, Turkey

Correspondence: PG Firat, Firat Mahallesi, Hastane Caddesi, No:54/5 44200, Malatya 44300, Turkey Tel: + 9042231680 38; Fax: + 9042223410660 . E-mail: pembeglbozgl@ yahoo.com

Received: 3 May 2011 Accepted in revised form: 7 September 2011 Published online: 11 November 2011

\begin{abstract}
Purpose To evaluate the influence of silicone hydrogel contact lenses on the intraocular pressure (IOP) measurement using Goldmann applanation tonometry (GAT), non-contact tonometry (NCT), and Pascal dynamic contour tonometry (DCT).

Methods We included in the study 40 eyes of 40 patients who did not have any ocular or systemic diseases or contraindications to contact lens use. We measured and recorded the IOP values of each patient using NCT without and with contact lenses (groups 1 and 2, respectively), using DCT without and with contact lenses (groups 3 and 4, respectively), and using GAT without contact lenses (group 5). Results The mean IOP value of group 1 was $14.55 \pm 2.95 \mathrm{~mm} \mathrm{Hg}$ and $13.92 \pm 2.58 \mathrm{~mm} \mathrm{Hg}$ in group 2 . We detected no statistically significant difference between group 1 and group 2 $(P=0.053)$. The mean IOP values for group 3 and group 4 were $16.26 \pm 2.33 \mathrm{~mm} \mathrm{Hg}$ and $15.19 \pm 2.40 \mathrm{~mm} \mathrm{Hg}$, respectively. We detected a statistically significant difference between groups 3 and $4(P=0.005)$. Group 5's mean IOP value was $12.97 \pm 2.65 \mathrm{~mm} \mathrm{Hg}$. IOP values measured with DCT were statistically significantly higher compared with IOP values measured with NCT and GAT $(P<0.0001$ and $P<0.0001$, respectively). Additionally, IOP values measured with NCT were statistically significantly higher compared with IOP values measured with GAT $(P<0.0001)$.

Conclusion According to the results of our study, silicone hydrogel soft contact lens use does not significantly affect IOP values measured with NCT, but it affects IOP values measured with DCT.

Eye (2012) 26, 278-282; doi:10.1038/eye.2011.271; published online 11 November 2011
\end{abstract}

PG Fırat', C Cankaya², S Doganay ${ }^{1}$, M Cavdar ${ }^{1}$, S Duman ${ }^{1}, \mathrm{E} \mathrm{Ozsoy}^{3}$ and B Koc ${ }^{4}$

Keywords: dynamic contour tonometry; non-contact tonometry; goldmann applanation tonometry; contact lens

Introduction

Soft contact lenses are used for cosmetic and therapeutic purposes besides the correction of refractive errors. Their use for refractive purposes has gradually increased due to advantages like providing maximum vision functioning and not causing esthetic discomfort. ${ }^{1}$

In addition to their optic indications, soft contact lenses are an effective treatment method for persistent epithelial defects, recurrent corneal erosions, filamentous keratitis, corneal surface irregularities, corneal abrasions, corneal thinning, bullous keratopathy, thermal and chemical burns, and after refractive surgery and ocular surface reconstruction. ${ }^{2}$ The frequent removal of contact lenses used for therapeutic purposes in types of corneal diseases affects epithelization and the recovery process negatively. ${ }^{2}$ In cases where contact lens removal is not desired, frequent measurement of intraocular pressure (IOP) may be needed. In these patients, obtaining accurate IOP values on contact lenses is significant in terms of follow-up and treatment of the patient. The removal of contact lenses causes temporal changes in IOP in addition to impairment of the epithelization process., ${ }^{2,3}$

The measurement of IOP is especially significant in the diagnosis and treatment of cases with glaucoma. Thus, accurately measuring IOP independently from various corneal factors is gradually gaining importance. At present, Goldmann applanation tonometry (GAT) is a widely used method of IOP 
measurement and is accepted as the gold standard, although it is affected by some corneal factors such as central corneal thickness (CCT). The other two measurement methods are non-contact tonometry (NCT) and Pascal dynamic contour tonometry (DCT). NCT enables an IOP measurement without contact by insufflating air to the corneal surface. DCT has been introduced as a novel contact method to measure IOP by matching the corneal contour. DCT obtains values independent from corneal thickness and corneal curvature by making a direct and constant IOP measurement. ${ }^{4}$

In our study, we investigated the influence of silicone hydrogel contact lenses on the IOP measurement using different tonometries (GAT, NCT, and DCT).

\section{Materials and methods}

A total of 40 eyes of 40 patients (21 males, 19 females) who did not have any ocular or systemic disease were included in the study.

The inclusion criterion was a normal cornea confirmed with no degeneration or dystrophy after a full ophthalmologic examination. The exclusion criteria were any systemic or ocular disease or any history of ocular surgery. Subjects with corneal astigmatism higher than 2D were also excluded.

We obtained Institutional Review Board approval from the Human Research Ethics Committee at Inonu University. We also obtained informed consent from all of the subjects, and we conducted the study under the ethical standards outlined in the Declaration of Helsinki.

We performed a full ophthalmic examination on each subject, including a visual acuity measurement and a slit lamp biomicroscopy for anterior and posterior segment evaluation with a $90 \mathrm{D}$ lens. We measured CCT with a Pentacam Scheimpflug imaging system (rotating Scheimpflug camera; Oculus, Wetzlar, Germany). The instruments we used for IOP measurements were a Goldmann applanation tonometer mounted to a slit lamp (Haag-Streit, Bern, Switzerland), a non-contact tonometer (Topcon CT-80A Computerized Tonometer, Topcon, Tokyo, Japan), and a Pascal dynamic contour tonometer (SMT Swiss Microtechnology AG, Port, Switzerland). We applied one drop of local anesthetic agent $0.5 \%$ proparacaine before the Pascal DCT, and we applied a fluorescein strip before GAT.

In group 1, we used NCT to measure the IOP of each subject without a contact lens. In group 2, which consisted of the same subjects with a soft contact lens, we again used NCT to measure the IOP. We used Pascal DCT for the IOP measurements in group 3 and group 4, with the difference that in group 3 there was no contact lens, and in group 4 the same subjects wore a soft contact lens.
In group 5, we used GAT to measure the IOP of the subjects with no contact lens. As multiple consecutive IOP measurements with corneal applanation cause a statistically significant reduction of $\mathrm{IOP}^{5}$ we repeated all measurements at least three times, at 5-min intervals. First, we took the IOP measurements of naked eyes with NCT, DCT, and GAT, in that order. Then, we performed the same measurements $30 \mathrm{~min}$ after the insertion of soft contact lenses. The same operator measured the IOP with all three devices; however, an independent technician read off and recorded the results of the measurements to reduce the risk of bias.

The contact lenses used in this study were silicone hydrogel lenses (Focus Night \& Day, CIBA Vision Corp., Duluth, GA, USA) with $24 \%$ water content and $0 \mathrm{D}$ power. The base curvature and the diameter of the lenses were $8.60 \mathrm{~mm}$ and $13.80 \mathrm{~mm}$ respectively.

We performed statistical analyses with the Kolmogorov-Smirnov and paired $t$-tests. In all cases, we accepted $P$-values $<0.05$ as significant. A total of eight patients agreed to provide consent for undergoing multiple examinations to achieve reproducibility of measurements. We assessed intraobserver reproducibility using the results of two scanning sessions with GAT, NCT, and DCT conducted by an operator (PF). To assess intervisit reproducibility of the results, we compared the results obtained by the operator on the first day with the results of an additional scan conducted by the same operator a week later.

\section{Results}

Demographic characteristics of subjects are given in Table 1 . The mean IOP value of group 1 was $14.55 \pm 2.95 \mathrm{~mm} \mathrm{Hg}$ and $13.92 \pm 2.58 \mathrm{~mm} \mathrm{Hg}$ in group 2 . The mean IOP values for group 3 and group 4 were $16.26 \pm 2.33 \mathrm{~mm} \mathrm{Hg}$ and $15.19 \pm 2.40 \mathrm{~mm} \mathrm{Hg}$, respectively. Group 5's mean IOP value was $12.97 \pm 2.65 \mathrm{~mm} \mathrm{Hg}$ (Table 2 and Figure 1).

Measured with NCT, we found no statistical difference between group 1 and group $2(P=0.053)$. We used Pascal DCT for group 3 and group 4, and a statistically significant difference was obtained between these two groups $(P=0.005)$.

Table 1 Demographic characteristics of the subjects

\begin{tabular}{lccc}
\hline $\begin{array}{l}\text { Gender } \\
\text { (male/female) }\end{array}$ & $\begin{array}{c}\text { Age } \\
\text { (years) }\end{array}$ & $\begin{array}{l}\text { Refractive } \\
\text { error }(D)\end{array}$ & CCT $(\mu \mathrm{m})$ \\
\hline $21 / 19$ & $34.57 \pm 9.94$ & $-0.15 \pm 0.72$ & $545.67 \pm 40.28$
\end{tabular}

Abbreviations: CCT, central corneal thickness; D, diopter.

The data are presented as the mean \pm SD. 
Table 2 IOP measurements with and without contact lens

\begin{tabular}{|c|c|c|c|c|}
\hline & \multicolumn{2}{|c|}{ Mean $I O P \pm S D$} & \multirow{2}{*}{$\begin{array}{c}\text { Mean difference } \pm S D \\
\text { between IOP measurements } \\
\text { with and without } \\
\text { contact lens }\end{array}$} & \multirow[t]{2}{*}{ P-value } \\
\hline & $\begin{array}{l}\text { Without } \\
\text { contact } \\
\text { lens }\end{array}$ & $\begin{array}{c}\text { With } \\
\text { contact } \\
\text { lens }\end{array}$ & & \\
\hline NCT & $14.55 \pm 2.95$ & $13.92 \pm 2.58$ & $0.62 \pm 1.98$ & 0.053 \\
\hline DCT & $16.26 \pm 2.33$ & $15.19 \pm 2.40$ & $1.06 \pm 2.24$ & 0.005 \\
\hline GAT & $12.97 \pm 2.65$ & & & \\
\hline
\end{tabular}

Abbreviations: DCT, Pascal dynamic contour tonometry; GAT, Goldmann applanation tonometry; NCT, non-contact tonometry. $P$-value: results of paired $t$-test.

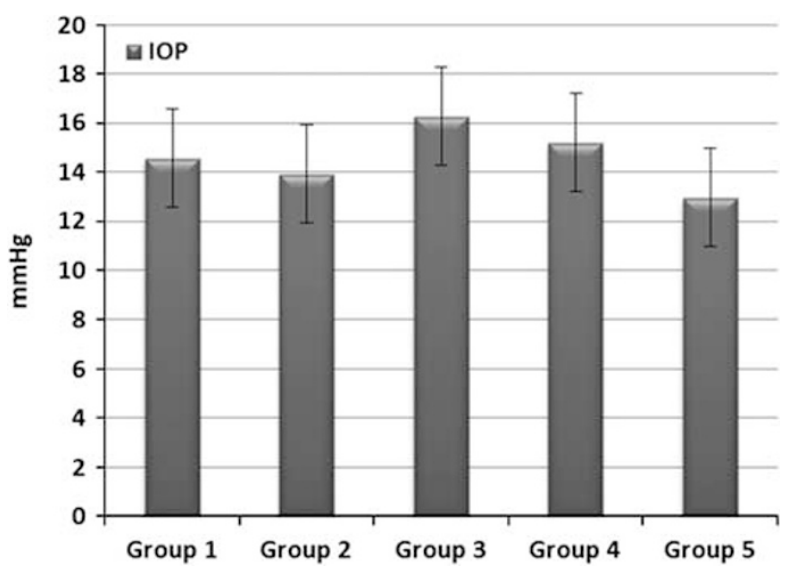

Figure 1 Comparison of the IOP measurements between the groups. Error bars indicate the SD of the values. Group 1: IOP measurement with NCT without contact lens, group 2: IOP measurement with NCT with contact lens, group 3: IOP measurement with Pascal DCT without contact lens, group 4: IOP measurement with DCT with contact lens, group 5: IOP measurement with Goldmann applanation tonometry.

We found that measurements taken with Pascal DCT were statistically significantly higher than the measurements taken with NCT $(P<0.0001)$. Also, NCT measurements were statistically significantly higher than GAT measurements $(P<0.0001)$. Similarly, the measurements we took using Pascal DCT were higher than the GAT measurements, with a statistically significant difference between them $(P<0.0001)$.

The reproducibility of measurements is shown in Table 3. Demographic characteristics of the patients in the reproducibility study are shown in Table 4 .

\section{Discussion}

In this study, we compared the IOP measurements in the absence and presence of a silicone hydrogel soft contact lens taken with three ophthalmic devices, GAT, NCT, and Pascal DCT.
In group 1 and group 2, we used NCT to measure IOP. There were no statistical differences between these two groups. Recent studies showed that IOP measurements over a contact lens with NCT depend on the lens power and material. ${ }^{6,7}$ Patel et al studied the effect of contact lens power and water content on the measurement of IOP with NCT. According to this study, NCT can be performed without significant error over a contact lens that has high water content and lens power $<+3 \mathrm{D} .^{8}$ In another study, Liu et al compared the IOP using NCT taken without a lens and with different myopic lens powers. They found statistically significantly decreased IOP values in lens power $-6.0 \mathrm{D}$ and below. ${ }^{9}$ Many studies demonstrated that IOP measurement with a contact lens using NCT can be obtained with no significant change. ${ }^{10,11}$ Matching this result, a silicone hydrogel contact lens did not influence the IOP measurement with NCT in our study.

In group 3 and group 4, we measured IOP with Pascal DCT. When we compared the results, there was a statistically significant difference with a contact lens vs without one. DCT uses a contour matching principle, which ensures that IOP measurement is less affected by corneal properties. Many studies have investigated this data. Kniestedt et $a l^{12}$ used human cadaver eyes to obtain IOP with DCT, GAT, and pneumatonometry, and they demonstrated that IOP values obtained with DCT were closer to the manometric pressure than those obtained with GAT and pneumatonometry. However, this was an in vitro study and must be confirmed by in vivo studies. Nosch et $a l^{13}$ investigated IOP readings over a thin hydrogel contact lens with DCT. They reported that a thin contact lens does not affect the IOP measurement accuracy. The different results found in the present study may be attributable to different study designs. In our study, we obtained the IOP measurements $30 \mathrm{~min}$ after the insertion of a soft contact lens, first with NCT and then with DCT. Similarly to our results, recent studies demonstrated that contact lenses induce corneal edema and cause statistically significant differences in IOP values with and without contact lens using GAT and DCT. ${ }^{14,15}$

In our study, we obtained the highest IOP value with Pascal DCT and the next highest with NCT. GAT measurements were the lowest of all. Hsu et al compared GAT, NCT, Tono-Pen tonometry, and DCT measurements. Similarly to our results, they found that DCT readings were the highest and GAT readings were the lowest. ${ }^{16}$ Several studies compared the IOP measurements obtained with GAT and DCT, ${ }^{17,18}$ as well as those with GAT and NCT. ${ }^{19}$ In most of these studies, mean GAT measurements were lower than the mean DCT and NCT values. Pache et $a l^{20}$ found that the mean pressure difference between GAT and DCT is $\sim 1 \mathrm{~mm} \mathrm{Hg}$. 
Table 3 Reproducibility of the measurements

\begin{tabular}{|c|c|c|c|c|c|c|c|c|c|c|c|c|c|c|c|c|c|c|}
\hline & \multicolumn{6}{|c|}{$N C T(\mathrm{n}=8)$} & \multicolumn{6}{|c|}{$D C T(\mathrm{n}=8)$} & \multicolumn{6}{|c|}{$G A T(\mathrm{n}=8)$} \\
\hline & \multicolumn{3}{|c|}{$\begin{array}{c}\text { Intraobserver } \\
\begin{array}{c}95 \% \text { confidence } \\
\text { of interval }\end{array}\end{array}$} & \multicolumn{3}{|c|}{$\begin{array}{l}\text { Interobserver } \\
95 \% \text { confidence } \\
\text { of interval }\end{array}$} & \multicolumn{3}{|c|}{$\begin{array}{c}\text { Intraobserver } \\
\text { 95\% confidence } \\
\text { of interval }\end{array}$} & \multicolumn{3}{|c|}{$\begin{array}{c}\text { Interobserver } \\
\text { 95\% confidence } \\
\text { of interval }\end{array}$} & \multicolumn{3}{|c|}{$\begin{array}{c}\text { Intraobserver } \\
\text { 95\% confidence } \\
\text { of interval }\end{array}$} & \multicolumn{3}{|c|}{$\begin{array}{c}\text { Interobserver } \\
\begin{array}{c}95 \% \text { confidence } \\
\text { of interval }\end{array}\end{array}$} \\
\hline & ICC & $\begin{array}{l}\text { Lower } \\
\text { bound }\end{array}$ & $\begin{array}{l}\text { Upper } \\
\text { bound }\end{array}$ & ICC & $\begin{array}{l}\text { Lower } \\
\text { bound }\end{array}$ & $\begin{array}{l}\text { Upper } \\
\text { bound }\end{array}$ & ICC & $\begin{array}{l}\text { Lower } \\
\text { bound }\end{array}$ & $\begin{array}{l}\text { Upper } \\
\text { bound }\end{array}$ & ICC & $\begin{array}{l}\text { Lower } \\
\text { bound }\end{array}$ & $\begin{array}{l}\text { Upper } \\
\text { bound }\end{array}$ & ICC & $\begin{array}{l}\text { Lower } \\
\text { bound }\end{array}$ & $\begin{array}{l}\text { Upper } \\
\text { bound }\end{array}$ & ICC & $\begin{array}{l}\text { Lower } \\
\text { bound }\end{array}$ & $\begin{array}{l}\text { Upper } \\
\text { bound }\end{array}$ \\
\hline $\begin{array}{l}\text { IOP without } \\
\text { contact lens }\end{array}$ & 0.938 & 0.745 & 0.975 & 0.903 & 0.624 & 0.979 & 0.945 & 0.773 & 0.989 & 0.972 & 0.872 & 0.994 & 0.927 & 0.706 & 0.985 & 0.938 & 0.747 & 0.987 \\
\hline $\begin{array}{l}\text { IOP with } \\
\text { contact lens }\end{array}$ & 0.814 & 0.535 & 0.959 & 0.806 & 0.515 & 0.957 & 0.914 & 0.662 & 0.982 & 0.851 & 0.636 & 0.968 & & & & & & \\
\hline
\end{tabular}

Abbreviations: DCT, Pascal dynamic contour tonometry; GAT, Goldmann applanation tonometry; ICC, intraclass correlation coefficient; NCT, non-contact tonometry.

Table 4 Demographic characteristics of the subjects for reproducibility

\begin{tabular}{lccc}
\hline $\begin{array}{l}\text { Gender } \\
\text { (male/female) }\end{array}$ & $\begin{array}{c}\text { Age } \\
\text { (years) }\end{array}$ & $\begin{array}{l}\text { Refractive } \\
\text { error }(D)\end{array}$ & CCT $(\mu \mathrm{m})$ \\
\hline $4 / 4$ & $37.75 \pm 8.58$ & $-0.15 \pm 0.68$ & $536.87 \pm 51.13$ \\
\hline
\end{tabular}

Abbreviations: $\mathrm{CCT}$, central corneal thickness; $\mathrm{D}$, diopter. The data are presented as mean \pm SD.

Several studies compared the reproducibility and reliability of IOP measurements obtained with NCT, DCT, and GAT. ${ }^{21-24}$ In most of these studies, similar reproducibility and reliability were demonstrated with all three devices. In this study, however, the results indicated better reproducibility of measurements for NCT, DCT, and GAT without a contact lens than with one.

To our knowledge, this is the first study investigating the influence of a silicone hydrogel contact lens on measurements taken with NCT and Pascal DCT and comparing them to GAT measurements. As a result, we found that a silicone hydrogel contact lens did not significantly influence the IOP measurements using NCT and Pascal DCT. On the other hand, when we compared the devices' IOP values, the highest values were taken with Pascal DCT, then NCT, and finally GAT. The differences between the values among the three devices were statistically significant.

\section{Summary}

\section{What was known before}

- Intraocular pressure measurements over a contact lens with non-contact tonometry depend on the lens power and material. These results are the sum of many studies.

What this study adds

- This is the first study comparing the IOP measurements between NCT, Pascal DCT, and GAT over a soft hydrogel contact lens in a clinical study.

\section{Conflicts of interest}

The authors declare no conflict of interest.

\section{References}

1 Guillon M, Maissa C. Long-term effects of the extended wear of senofilcon A silicone hydrogel contact lenses on ocular tissues. Optometry 2010; 81: 671-679.

2 Khan JA, Graham CE. Effect of contact lenses removal or displacement on intraocular pressure. Arch Ophthalmol 1991; 109: 825-828.

3 Blackmore SJ. The use of contact lenses in the treatment of persistent epithelial defects. Cont Lens Anterior Eye 2010; 33: 239-244.

4 Tonnu PA, Ho T, Newson T, El Sheikh A, Sharma K, White $\mathrm{E}$ et al. The influence of central corneal thickness and age on intraocular pressure measured by pneumotonometry, non-contact tonometry, the Tono-Pen $\mathrm{XL}$, and Goldmann applanation tonometry. $\mathrm{Br} J$ Ophthalmol 2005; 89: 851-854.

5 Almurad TM, Ogbuehi KC. The effect of repeated applanation on subsequent IOP measurements. Clin Exp Optom 2008; 916: 524-529.

6 Lim L, Ng TP, Tan DT. Accurate intraocular pressure measurement in contact lens wearers with normal pressures. CLAO J 1997; 23: 130-133.

7 Zeri F, Lupelli L, Formichella P, Masci C, Fletcher R. Goldmann applanation tonometry over daily disposible contact lens: accuracy and safety of procedure. Contact Lens Anterior Eye 2007; 30: 233-238.

8 Patel S, Illahi W. Non-contact tonometry over soft contact lenses: effect of contact lens power on the measurement of intra-ocular pressure. Contact Lens Anterior Eye 2004; 27: 33-37.

9 Liu YC, Huang JY, Wang IJ, Hu FR, Hou YC. Intraocular pressure measurement with the noncontact tonometer through soft contact lenses. J Glaucoma 2011; 20: 179-182.

10 Panek WC, Boothe WA, Lee DA, Zemplenyi E, Pettit TH. Intraocular pressure measurement with the tono-pen through soft contact lenses. Am J Ophthalmol 1990; 109: $62-65$.

11 Sugimoto-Takeuchi R, Yamamoto R, Kuwayana T, Kinoshita S. Effect of intraocular measurement through therapeutic soft 
contact lenses by noncontact tonometer. Nippon Ganka Gakkai Zasshi 1991; 95: 869-872.

12 Kniestedt C, Nee M, Stamper RL. Accuracy of dynamic contour tonometry compared with applanation tonometry in human cadaver eyes of different hydration states. Graefes Arch Clin Exp Ophthalmol 2005; 243: 359-366.

13 Nosch DS, Duddek AP, Hermann D, Stuhrmann OM. Dynamic contour tonometry (DCT) over a thin daily disposable hydrogel contact lens. Contact Lens Anterior Eye 2010; 33: 219-214.

14 Oh HJ, Yoo C, Kim YY, Kim HM, Song JS. The effect of contact lens-induced corneal edema on Goldmann applanation tonometry and dynamic contour tonometry. Graefes Arch Clin Exp Ophthalmol 2009; 247: 371-375.

15 Hamilton KE, Pye DC, Kao L, Pham N, Tran AQ. The effect of corneal edema on dynamic contour and Goldmann tonometry. OptomVis Sci 2008; 85: 451-456.

16 Hsu S-Y, Sheu M-M, Hsu A-H, Wu KY, Yeh JI, Tien JN et al. Comparison of intraocular ocular pressure measurements: Goldmann applanation tonometry, noncontact tonometry, Tono-Pen tonometry, and dynamic contour tonometry. Eye 2009; 23: 1582-1588.

17 Barleon L, Hoffmann EM, Berres M, Pfeiffer N, Grus FH. Comparison of dynamic contour tonometry and goldmann applanation tonometry in glaucoma patients and healthy subjects. Am J Ophthalmol 2009; 142: 583-590.

$18 \mathrm{Ku}$ JY, Danesh-Meyer HV, Craig JP, Gamble GD, McGhee CN. Comparison of intraocular pressure measured by Pascal dynamic contour tonometry and Goldmann applanation tonometry. Eye 2006; 20: 191-198.

19 Martinez-de-la-Casa JM, Jimenez-Santos M, Saenz-Frances F, Matilla-Rodero M, Mendez-Hernandez C, Herrero-Vanrell R et al. Performance of the rebound, noncontact and Goldmann applanation tonometers in routine clinical practice. Acta Ophthalmol 2011; 89: 676-680.

20 Pache M, Wilmmeyer S, Lautebach S, Funk J. Dynamic contour tonometry versus. Goldmann applanation tonometry: a comparative study. Graefe's Arch Clin Exp Ophthalmol 2005; 243: 763-767.

21 Lam AK, Chan R, Lam CH. The validity of a new noncontact tonometer and its comparison with Goldmann tonometer. Optom Vis Sci 2004; 81: 601-605.

22 Regine F, Scuderi GL, Cesareo M, Ricci F, Cedrone C, Nucci C et al. Validity and limitations the Nidek NT-4000 non-contact tonometer: a clinical study. Ophthal Physiol Opt 2006; 26: 33-39.

23 Carbonaro F, Andrew T, Mackey DA, Spector TD, Hammond CJ. Comparison of three methods of intraocular pressure measurement and their relation to central corneal thickness. Eye 2010; 24: 1165-1170.

24 Kotecha A, White E, Schlottmann PG, Garway-Heath DF. Intraocular pressure measurement precision with the Goldmann applanation, dynamic contour, and ocular response analyzer tonometers. Ophthalmology 2010; 117: 730-737. 